heart direase in early life is the result of acnte rheumatic infection-for all practical purposes other causes may be left out. The danger of fresh infection or the recrudescence of latent infection persists as a real one all through adolescence. Sometimes this will take the form of an acute flare-up-acute rheumatic fever; in other cases it will be manifested by slight pains in joints or tendons or muscles, symptoms which do not incapacitate the patient but are unfortunately often accompanied by fresh endocardial and myocardial inflam. mation. Consequently my own practice is to treat those patients all through adolescent life with sodium salicylate. This need not be given continuously, but for a week or ten days in every month the patient should take from 40 to 60 grains of sodium salicylate daily. This is the best preventive treatment of further infection which I know.

Those patients who have a cardiac lesion but who present no symptoms under the ordinary routine of life had better be left alone so far as any lieart treatment is concerned. In giving advice about their future life and work one will naturally select some occupation which does not involve great physical strain.

Those patients who have a cardiac lesion and who find that any extra exertion induces symptoms such as breathlessness had better be advised to observe their own limitations. Games and exercises should be regulated so as not to tire out the patient or produce cyanosis and breathlessness. In selecting a suitable occupation for their adult life it will probably be best for them to take up work of a sedentary nature so that the exercise they take may be independent of their work and not part and parcel of it.

Those patients who have a cardiac lesion accompanied by breathlessness and distress on any exertion do not require to be specially restricted. Nature will teach them to go slow and not to do themselves harm. They have permanently damaged and disabled hearts.

During adolescent life there is less call for direct treatment of the heart than either before or after. This is fortunate, for it spares me the trouble of going into the nature of efficient and direct cardiac treatment. I am afraid I should only have exposed my own want of knowledge of the whole subject of cardiac tonics and my utter scepticism as regards most of them. No one has yet discovered a tonic which will improve the action of a heart which has hypertrophied in order to overcome some permanent difficulty. No one has yet discovered a tonic which will restore that heart when once the muscular power has given out. The more one studies the action of the heart in health and in disease the more one is struck by its wonderful power in accommodating itself to meet the ever-varying calls of the circulation, and in overcoming the difficulties and new problems introduced as the result of disease. Of all the self-regulating mechanisms in the human economy there is none which surpasses the heart in the power of meeting difficulties in health and devieloping compensatory changes in disease. These inherent powers of producing compensatory clianges in the heart, largely through hypertrophy of the cardiac muscle, are specially manifested during adolescence and are not to be relied on to the same extent in adult life.

We can ease the work of a diseased and labouring heart by giving it partial rest. We can remove all physical strain by keeping the patient in bed. We can cut off the sources of nervous disturbance in the brain by sedatives and narcotics. We can deal to some extent with difficulties in the circula. tion owing to the engorgement of other organs or the presence of oedema and effusion. These things are possible, but when it comes to be a question of direct action on the heart, treatment directed to improve the action of a failing heart, we are apt to discover our therapeutic helplessness

Yet there is one condition in which the heart is disturbed and its action is impaired, not through the valvular lesion and not through myocardial exhaustion primarily, but as the result of an abnormally rapid rate. The cardiac force, as regards its pumping function, may be sufficient and the com pensatory changes may be in working order, but the beart muscle shows signs of failure owing to the rapid rate present. If the heart rate is much increased the resting time of diastole is curtailed, and in the cour'se of time exhaustion of the heart muscle follows. Many rheumatic hearts become disturbed at times during adolescence by the development of this rapid rate, which may be a regular action with a normal rhythm or an irregular action with an abnormal rhythm. In both of these cases it is the rapidity of the heart which is causing the trouble and which is calling for treatment. Under these conditions we can employ digitalis with great confidence, giving full doses for a few days, and we shall often find that when the heart is slowed the patient is much relieved as regards all the signs and symptoms of cardiac failure. I do not say that digitalis will act in all cases. Unfortunately it will not, and we cannot at present tell why it slows the heart in some cases while in others it fails to do so. But it remains as our great sheet-anchor in cases of cardiac failure associated with a rapid action of the ventricles.

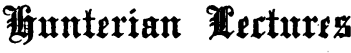

on

\section{MAN'S POSTURE: ITS EVOLUTION AND DISORDERS.}

Given at the Royal College of Surgeons of England BY

Professor Sir ARThUR KEITH, F.R,C.S., F.R.S., CONSERVATOR OF TEE MOSEUM.

[Abstracts.]

\section{LECTURE II.-THE EVOLUTION OF THE ORTHOGRADE SPINE.}

THE human spine is a mechanism of the ntmost complexity; between the sacrum and the skull are incorporated twentyfour vertebrae, each provided with three short levers-the spinous and transverse processes; each lever is furnished wtth, not a single muscle, but a group of them. As we pass from sacrum to skull we find the levers change in length, strength, shape, and direction. The muscles, too, which move and balance the levers alter in disposition and strength as we pass from vertebrae to vertebrae. The twelve dorsal vertebrae, besides their three short processes, are provided with very long and powerful levers-the ribs. The student is so apt to concentrate his attention on the respiratory action of the ribs that he forgets that they are the most powerful of the spinal levers. All the muscles attached to ribs-the intercostals, the rectus abdominis, and oblique muscles of the belly wall-are prime movers and balancer's of the spine. Here, then, is a very complex team for Nature to drive along a straight evolutionary course. By what process or processes did she succeed in transforming the multitude of spinal levers and muscles, which serve the needs of a pronograde monkey, into the forms which answer to the needs of man? Such a transformation seems lighly probable if we suppose that, in the course of its evolution, the human stock has passed through two intermediate stages: (1) a hylobatian stage, represented by the small orthograde apes-the gibbons; (2) a troglodylian stage, now represenied by great anthropoids such as the gorilla or chimpanzee.

The Sacralization of Body Segments.

With the evolution of the upright or orthograde spine there took place a shortening of the lumbar part of the spinal column, and $m y$ first effort will be to show you the means which Nature used to attain this end. In most pronogrado monkeys, both of the old world and of the new, the three vertebrae* which become modified in the course of development to form the sacrum are the twenty-seventh, twenty-eighth, and twenty-ninth of the spinal series; Professor Wingate Todd ${ }^{1}$ has given reasons for believing that the twenty-seventh vertebra formed the first of the sacral series in the earliest mammals. If one examines a number of monkeys of the same species it will be found that in some the twenty-seventh vertebra, in place of being purely sacral in its characters, shows some admixture of lumbar traits; in others, the twenty-sixth vertebra shows signs of forsaking some of its lumbar traits and adopting the characters of tho first sacral. There is a tendency in some for the process of sacralization to spread in a tailward direction; in others in a headward direction. In small orthograde apes, represented by the gibbons, sacralization has spread headwards, so that the twenty-sixth now forms the first of the sacral series. In this manner a lumbar vertebra has been added to the sacrum of gibbons, giving them four sacral vertebrae in place of the pronograde three, but reducing their lumbar

* See a paper I contributed to the Journal of Anatomy and Physioiogy. 1902 , vol. 37, p. 18. 
vertebrae to six in place of seven - the primitive number. The incidence of sacralization amongst gibbons is much less stable than among pronograde monkeys. In fully 15 per cent. of animals the process lias spread headwards, so that the twenty-fifth vertebra shows some or all of the characters of a first sacral; over 5 per cent. of animals show a tendency in an opposite or tailward direction. Amongst the great anthropoids the process of sacralization has spread still farther in a head ward direction. In the majority of chimpanzees the twenty-fifth has become the first sacral, but amongst orangs-an anthropoid type in which the lower limbs have undergone retrograde changes-the twentyfourth vertebra (fifth lumbar) forms the first of the sacral series. In man, as in the chimpanzee and gorilla, the twentyfifth forms the first of the sacral series; but in man the formula ${ }^{2}$ is more stable than among the large anthropoids. In a series of one hundred human skeletons it will be found that some three or four will show a headward sacralization, while six or eight will show a tailward movement. The evolution of the plantigrade posture has necessitated a lengthening of the loins in man - the tendency of sacralization in lim seems to be in a tailward direction.

\section{Shifting of Limb Buds.}

Now the developmental process which transforms a last lumbar into a first sacral vertebra is not one which works only on bones; all the elements which lie in the same segment of the embryonic body-nerve, muscle, and vessel-undergo a transmutation corresponding to that of the vertebra. With a headward sacralization there is also a forward movement of the sacral and lumbar plexuses, although the forward shift of the nerves lags slightly behind that of the vertebrae. In point of segmental origin the buds which form the lower limbs also move forwards; so also must the centres in the spinal cord which regulate the nerve mechanisms of the lower part of the body. We cannot conceive that the process of segmental differentiation which fashions the hinder body segments of ape and of man can be influenced by any intrinsic or extrinsic agent acting on the completely developed body. The evolutionary machinery which shapes new forms has to be sought for, not in the acquired habits of the living animal, as Lamarck supposed, but in the factors which control the development of embryonic tissues, and that evolationary machinery works in such a way as to produce new functional possibilities.

Trangudtation of Dorsal and of Cervical Segments.

In fashioning the lumbar region of man and of the higher primates the process of transmutation has also been at work, but to a less extent, in the body segments at the upper or dorsal end of the lumbar series. In the majority' of pronograde monkeys there are thirteen pairs of ribs; the last ribbearing vertebia is the twentieth. With the evolution of the orthograde posture in the small anthropoids the twentieth vertebra was still the last rib-bearer. In the most generalized surviving member of the great anthropoid group-the chimpanzee-the twentieth vertebra is usually tho last ribbearer; in the gorilla it is often the twenty-first; while in the orang, although it is usual to find the last rib attached to the nineteenth vertebra, yet it is not ancommon to find the process of costalization ending at the eighteenth. If we take a hundred 'human skeletons we shall find about two in which the eighteenth vertebra is the bearer of the lást rib, ninety in which it is the nineteenth, and eight in which it is the twentieth. There can be little doubt that man's immediate ancestry had thirtecn pairs of ribs; in every haman embryo a vestige of the thirteenth pair appears, which subsequently becomes fused witl the adjoining transverse process. The diaphragm is attaclued to the transverse processes of the first lumbar vertebra, representing the origin from the thirteenth pair of ribs, which is to be seen in nearly all apes. A tendency to the transmutation of the last cervical into a first dorsal or a first dorsal into a last cervical is to be recognized both in man and apes. But in apes, as in men, it is much commoner to see the last cervical vertebra assuming dorsal characters than the first dorsal assuming cervical characters. 'The tendency of the dorso-cervical morement, which is slight, is in a headward direction. There is no reason to suppose that in the crolution of the higher primates there has bcen an intercalation of new segments at any point of the vertebral series; segments have been shed, but always it is the hindmost segments of the body which disappear.
Why the Loins Were Shortened.

What, then, is the functional significance of the shortening of the lumbar region which has taken place with the evolution of the orthograde posture? Why should this region be again elongated and strengthened when the human body became adapted to the plantigrade posture? In pronograde monkeys of the old world the lumbar part forms from 40 to 45 per cent. of the presacral spine; in small orthograde apes the lumbar region varies from 30 to 34 per cent. of the spine. I have already drawn attention to the fact that pronograde apes gain their forward impetus in leaping from their hind limbs; in the act of springing the thoracic part of their bodies is raised by extension of the loins; the lumbar part of their spine serves as a flexible lever for moving the upper part of their body on the fixed pelvic base. In the orthograde gibbon the lumbar region serves quite a different purpose. As the arms are the main organs of progression the lumbar part of the spine serves chiefly as a flexible lever for attaching the pelvis and lower limbs to the body; in its forward flight branches are seized by the feet for support and thus the weight of the body does come to rest temporarily on the lower limbs of the moving gibbon. Its lumbar spine serves alternately as a suspending and a supporting lever. 'The change from the pronograde to the orthograde posture was attended by a shortening of the lumbar region, brought about by the sacralization of the twenty-sixth body segment. There was at the same time an enormous saving in muscular expenditure. This will be evident when I lay the following observation, made on healthy jungle animals, before you. In a pronograde monkey $I$ found that the muscles employed in extending the spine-the erector spinae group-weighed 93.5 grams, while in the orthograde gibbon, although the weight of its body was rather more than that of the monkey, the erector spinae group weighed only 44.2 grams-less than balf the weight of the pronograde musculature.

\section{The Lumbar Curve.}

With the evolution of the great anthropoid type the lumbar region of the spine became still shorter and stronger. In the chimpanzee the lumbar part, on an average, forms 27 per cent. of the presacral spine; in the orang only 24 per cent.; in the gorilla rather more-namely, 29 per cent. In none of the great anthropoids is the whole weight of the upper parts of their bodies transmitted through the lambar region of the spine except momentarily. In its climbing movements tho chimpanzee makes an equal use of its upper and lower limbs in supporting its weight; in the orangs the upper extremities are the predominant supporting - or rather suspendingorgans for its natural arboreal progression; in gorillas the lower extremities are more specialized than the upper for purposes of support and movement. With the evolution of the human or plantigrade posture the lumbar region of the spine became further modified and strengthened to form a flexible lever on which the whole weight of the upper part of the body is poised. An easy and graceful carriage of the human body requires long. loins. At birth the lumbar region measures 27 per cent. of the presacral spine-tho same proportion as in the chimpanzee. Elongation takes place rapidly as a child learns to walk; in the average adult the lumbar region comes to form about 32 per cent. of the total length of the spine. Indeed, it is not too much to say that the spine of the human baby, as regards the proportions of its parts and its curvatures, is in an anthropoid or troglodytian phase of evolution. We have only to watch an infant trying to support its body erect.when learning to walk to see reproduced the orthograde posture of a great anthropoid ape. The lower limbs are seen to be imperfectly extended, the body plainly inclines forwarảs, and the arms stretch out to clutch at neighbouring objects for support. In the second year of life, growth changes in the lumbar vertebrae make further extension of the body a permanent possibility; it is then that the loins elongate and the lumbar curre, seen only in the human species, makes its appearance.

\section{Alterations in the Musculature.}

When we compare the spinal musculature of a pronograde monkey with that of the various orthograde forms, including man, we are struck by the simple nature of the structural modifications which have served to adapt the pronograde system of muscles to orthograde purposes. Not a single new muscle has been introduced; everywhere we meet with the same series of vertebral levers and the same groups of muscles acting on them. The brunt of the evolutionary or 
a laptational changes has fallen on the spinal musculature of the lumbar regiou. True it is that certain changes take place in the muscles which extend the dorsal part of the spine, but the moulding of the dorsal region has more to do with respiratory purposes than for the mere support of the body in an upright posture. The musculature of the cervical region also undergoes certain changes with the evolution of the orthograde forms, but the chief transformations seen in this region of the spine do not depend on postural adaptations, but on jaw and tooth development. The neck is the movable lever of the head; if there are massive jaws and great teeth then must the skull be widely hafted to a strong and thick neck. 'There is a growth mechanism which correlates the development of neck and jaws.

\section{Establishment of a Pelvic Base.}

We turn, then, to note the chief changes which have taken place in the spinal musculature of the loins of higher primates; they provide a series which lead from the condition seen in pronograde monkeys to that seen in orthograde, plantigrade man. As we pass along the series we note that the spinal musculature obtains an ever-increasing attachment to the sacrum and to the pelvis; the pelvis becomes more and more a fixed base from which the erector spinae may act. The steps which led up to the great pelvic base of man were the following: (1) With, or before, the assumption of the orthograde posture, the tail as a free external organ completely disappeared; in every member of the orthograde the tail vertebrae have become submerged and coccygealized. The disappearance of the extensors of the tail leaves the dorsal surface of the sacrum free for the use of the erectors of the spine. (2) The sacraliza. tion of the seventh and then of the sixth lumbar vertebra extends and strengthens the area for spinal fixation. (3) An enormous extension of the iliac crests, particularly in a dorsal direction, gives an increased base for fixation of spinal muscles. The dorsal extension of the iliac crests reaches its climax in the human pelvis. In the gibbon the ilium and its crest are shaped much as in monkeys; the transformation has become marlsed in the great anthropoids, the gorilla showing the nearest approach to man in the development of its iliac crests. (4) In man the area for muscular origin is also increased by the backward tilting of the sacrum, so that its dorsal surface in the erect position looks upwards as well as backwards.

SpoNDYLOLISTHESIS.

This oblique, in many individuals almost horizontal, position of the human sacrum deserves our particular attention. Everyone must have observed how variable is the depth of the curvature of the loins; in some individuals the sacral aspect of the pelvis forms almost a horizontal shelf. In certain races, particularly negro and negroid, the loins are straight; the sacrum seems to almost continue the line of the lumbar spine; in other races, particularly in Europeans and more in women than in men, the sacrum forms almost a right angle to the lumbar spine. The spine, transmitting the weight of the suprapelvic part of the body, is poised on the anterior or basal end of the sacrum. The weight tends to tilt up the hinder or coccygeal end of the sacrum, and would do so were it not for (1) the form and strength of the sacroiliac joints, (2) because the hinder end of the sacrum is bound to the ischial tuberosities by those particularly strong stays, the sacro-sciatic ligaments. There is also a tendency, when the sacrum is set obliquely, for the basal end of the spine to ke dislocated forwards into the pelvis, giving rise to the condition known as spondylolisthesis. Such a dislocation is prevented by the articular processes of the last lumbar vertebrae being locked within those of the sacrum. A sudden jump, or severe effort to lift or carry a heavy weight, may cause the laminar arch of the last lumbar vertebra to snap and thus permit a forward displacement of the spine. I know of no evidence which leads me to suppose that the separation of the arch of the last lumbar vertebra is the result of malderelopment.

\section{Adaptarions for Lateral Balance.}

We have been discussing the evolutionary changes seen in the sacrum and pelvis of apes and men-changes which were required to give a more extensive and firmer base from which the erector muscles could act. We note that the pelvic base becomes wider. The reason for this is quite clear. The spine of a pronograde monkey, if converted to serve the needs of the orthograde posture, will require special adaptations, not only for extensiou and flexion, but also for lateral movements and balance. As the ribs are by far the most powerful lateral levers, it was by a modification of them, and of the muscles acting on them, that lateral balance in the orthograde postare was secured. The thorax was transformed in shape, not for respiratory but for postural purposes. Every costal are is made up of three segments-a dorsal, to which the spinal muscles are attaclied; a lateral, which is acted on by the intercustals and oblique muscles of the belly wall; a ventral or anterior segment, to which the rectus abdominis is inserted. Every muscle attaslied to a rib is also a spinal balancer. With the evolution of the orthograde posture one notes that the dorsal segments of the ribs became increased in length, thus giving the spinal muscles a greater lateral purchase on the spine. Further, they became set farther back-more on the plane of the tips of the spinous processes-thus giving the muscles attached to the clorsal segments of the ribs a greater power in extending the spine and keeping it erect. Thus, in the orthograde types the bodies of the dorsal vertebrae have the appearance of being pushed farther within the cavity of the thorax than in pronograde types.

The Orthograde Adaptatrong seen in Spinal Muscles.

In the course of a single lecture it is impossible to give a detailed account of all the changes which are seen to take place in the spinal musculature with the evolution of the orthograde posture. But I may cite one or two instances to illustrate the manner in which evolutionary changes are effected. The quadratus lumborum of $\operatorname{man}$ is a lateral balancer of the spine. It rises from the iliac crest and is attached to the transverse processes of the lumbar vertebrae and to the last rib; some of the fibres to the last rib rise from the transverse processes. The quadratus of the great anthropoid apes is similar in form and action to that of man. In pronograde apes this muscle forms a series of fasciculi acting on the transverse processes of the loins; the hinder. most of these springs from the iliac crest; the most anterior end on the last one or two ribs. The fasciculi adjust the lumbar vertebrae by acting on their transverse levers. The quadratus of the gibbon is, as regards form and action, intermediate to the stages seen in monkeys and great anthropoids. Evolution has proceeded by ccmbining a series of independent fasciculi, acting individually, to form a single muscle which acts on a region of the spine rather than on individual vertebrae.

The changes which came over the deepest layer of the spinal musculature-particularly in the muscle known in liuman anatomy as the multifidus spinae-were of a similar nature. In the great anthropoids we find the spinalis dorsi assuming the form seen in man. With the evolution of the orthograde posture not a single new muscle was introduced in the spinal series; yet all became modified, some to a slight extent and some to a great extent. But in all cases the machinery of evolution is the same; it consists of partial or complete migration of muscular attachments; a fusion or separation of fasciculi; under- or over-development of the various constituent parts of a muscle.

The Conplexity of the Physiological Problem.

It is when we concentrate our attention, not on the anatomy but on the physiology of the spinal musculature that we realize the complexity of the problem implied by the evo'u. tion of the orthograde posture. In pronograde mammals, be they four-footed or four-handed, each vertebra has to be adjusted by muscular action so long as the animal sits, walks, or stands. In orthograde primates each vertebra has to be balanced on another, so long as the erect or semi-erect position is maintained. Their thick intervertebral discs make balance more delicate. A little sum in arithmetic will help us to understand what a living vertebral balance means. In the spine of the commoner kinds of monkeys there are twenty-six vertebrae; each is provided with three short levers; thirteen of them have in addition the long and powerful costal levers-104 levers all told. On an average four muscles act on each lever-416 muscles in all. From each of these muscles constant streams of impulses are passing into the nerve centres of the cord and equally con. stant streams are emerging to maintain the postural tone and actions of the muscles. Besides these streams of afferent and efferent impulses there are the equally extensive higher streams flowing to and from the postural centres of the mid. brain and the timing mechanisms in the carebellum and bulb. The nerve centres of the spinal cord, mid-brain, and hind brain of a monkey are organized to carry out the reflexes necessary for a pronograde posture. It is habitual for monkeys of all kinds to assume a sitting or semi-erect posture when 
resting; to maintain this attitude the nerve mechanisms must have in them a nucleus which may have been expanded into that elaborate mechanism which serves the needs of orthograde apes.

\section{Scouigsis.}

In none of the orthograde forms is such a continuous and urgent demand made on the postural spinal mechanism as is the case in man. In man only is the whole weight of the suprasacral part of the body supported erect on the spine over long intervals. The demand on this neuro-muscular postural mechanism is, I think, even greater in the sitting than in the standing posture, particularly if we sit leaning forwards in writing and reading. Sitting bolt upright is particularly exhausting, more especially for young people in whom growth of vertebrae and of spinal muscles is proceeding apace. The muscles which act on the short levers of the spine yield first, while the muscles which act on the long costal levers can still keep on. We rest these exhausted short spinal muscles by allowing the vertebrae to rotate until the articular processes begin to lock ard the transverse processes rest upon the necks of the long costal levers. Herein lies the beginning of lateral curvature or scoliosis. If the habit becomes fixed, then como the deformities of chest, vertebrae, and spine with which ortho. paedic surgeons are only too familiar. It is not true, however, to say that our spines are not perfectly adapted to the upright posture; it would be more accurate to say that human spines were not evolved to withstand the monotonous and trying postures entailed by modern education and by many modern industries.

REFERENCES.

1 T. Wingate Todd: inat. Record, 19<3, vol. 24, p. 251. ${ }^{2}$ See Wingate Todd, loc. cit.; A. Keith: Journ. of Anat., 1902, vol. 37, p. 18.

\section{đilhe (ronlstonian Pertures}

ON

\section{THE NATURE OF ARTERIO-SCLEROSIS.}

\author{
Delivered before the Royal College of Physicians \\ OF LONDON \\ BY
}

GEOFFREY EVANS, M.D.CantaB., F.R.C.P.Lond., ASSIBTAN I DIRECTOR, MEDICAL T NIT, AND ASBISTANT PHYGICIAN, ST. BART JUIOMEW's HOSPITAL.

\section{Lecture II.-THE INTRINSIC PROCESS IN ARTERIO. SCLEROSIS.*}

Tre histology and distribution of diffuse hyperplastic sclerosis formed the subject of the last lecture. The nature of the process concerned in the development of the lesion is the next aspect of its pathology to be considered. From a theoretical standpoint one or more of four cardinal pro. cesses are involved-namely, Involution, Growth, Inflammation, and Degeneration. The subject is a difficplt one to present concisely, and if it is dealt with from an abstract point of view its presentation is liable to be either too dogmatic or ambiguous; hence I have chosen a chief advocate for each theory, and will discuss the theory on the basis of the argument and facts brought forward to support it.

\section{Physiological Processes.}

(a) The Process of Involution.

Thoma's ${ }^{1}$ view of arterio-sclerosis was based on the observation of the changes that take place in the a corta at birth on the interruption of the placental circulation. He observed an intimal thickening of the aorta between the origin of the ductus arteriosus and the origin of the umbilical arteries, due to cellular proliferation and new formation of connective tissue in the subendothelial layer, and, as Jores showed later, due also to the formation of elastic tissue in this layer. Thoma com. pared this change to the intimal thickening found in ligatured arteries and in the obliterated hypogastric arteries of infants, and he attributed it to a slowing of the blood stream. He applied this theory to the development of arterio-sclerosis. Thus, in the case of nodular sclerosis, he held that the intimal thickening was secondary to weakening of the media,

\footnotetext{
* Abstract of lectura delivered on March 8th.
}

as a result of which bulging of the vessel wall occurred, with consequent slowing of the blood stream at the site of bulging. In the case of diffuse arterio-sclerosis not due to initial weakening of the media he presumed a destruction of capillary fields by disease, and argued that as a result of reduction in the size of the vascular bed a slowing of the blood stream occurred in the vessels supplying the affected area. The theory involves the assumption that an artery may fail to adapt its lumen to the amount of blood flowing through it by contraction of the media, and that the necessary narrowing of the lumen is completed by thickening of the intima.

It is generally agreed that as a basic explanation of the development of arterio-sclerosis Thoma's theory does not not hold good. Thus, as Fuchs pointed out, there is no evidence of a failure on the pait of the aorta to equalize by muscular contraction the size of its lumen to the decreased quantity of blood flowing through it after cessation of the placental circulation. Further, it is inconceivable that in a system such as the cardio-vascular, which adapts itself so rapidly to changes in the distribution and quantity of blood content, a single alteration in these conditions could be re. sponsible for intimal thickening which gradually increases over a period of years. Thoma's premisses were also shown to be incorrect by the fact that the intimal changes in the aorta are not limited to the length of the vessel between the ductus arteriosus and the origin of the umbilical arter:es. Jores raised objection to the theory on histological grounds; he emphasized the fact that the intimal thickening in involu. tion is of the connective tissue or regenerative type, whereas in arterio-sclerosis it is of the hyperplastic type-a distinction based on the different form of elastic fibres in the two conditions. Marchand also attacked the theory on histological grounds, and pointed out the absence of fatty degeneration in arterial involution in contrast to its constant presence in arterio-sclerosis. The same fact bas come to my notice in studying the changes that take place in involution of the ductus arteriosus and hypogastric arteries of infants. There seemed to be an exception to the rule that fatty de. generation does not occur in arterial involution in the reported presence of fatty degeneration in uterine arteries undergoing normal involution, but, as I have shown $e^{\text {'sewhere, }}{ }^{2}$ the work which led to this opinion was based on the examination of pathological material, and the fatty change observed in the specimens examined was due to disease elsewhere and was not a part of the process of normal uterine involution.

Though 'Thoma's theory fails in providing a basic explanation of arterio-sclerosis, it probably holds good in so far as it includes the idea of replacement fibrosis. For instance, in the case of nodular sclerosis, if the primary lesion is in the intima Thoma's theory has no application, but if the initial lesion is in the media it may well be that the intimal proliferation occurring as a secondary event is compensatory. Thoma attempted to prove that the initial change was a weakening of the media by injecting arteries affected by nođular sclerosis with melted wax equivalent to the blood pressure during life, then allowing the wax to set and cutting sections of the artery. He claimed that the nodules disappeared and the lumen of the artery so distended had a normal cylindrical form. These experiments have been repeated by Klotz, ${ }^{3}$ who used water instead of wax, and cut the vessel frozen; he failed to confirm Thoma's results. Thoma also attempted to demon. s rate the primary weakening of the media by injection of the vasa vasorum of the larger vessels, and he showed that a greater penetration of the media by vasa viso:um occurred at certain points where there was no intimal thickening, and since this increase in vessels in the media was found in patches of nodular sclerosis he argued that the new formation of vessels showed a damage to the media as a primary event preceding the intimal proliferation. My own view of the matter is that Thoma's view of arterio-sclerosis holds good to the linited extent that it involves the idea of a replacenest fibrosis. To this extent it is in keeping with the inflam. matory theory of arterio-sclerosis, and it is of this further value-that it brings out the fact that degenerative clianges are a primary event in one form at least of arterio-sclerosia. Yet even when the degenerative changes are primary it cannot be assumed that the intimal proliferation is necessarily of the nature of a replacement fibrosis, since the proliferation may be a direct response to the insult that is simultaneously responsible for the medial degeneration. Thus Thoma's theory is merely an adjunct to any basic explanation of the production of the lesion in arterio-sclerosis. 